\title{
Unusual accident during proximal ventricular shunt catheter removal in an infant: a case report
}

Gabriele Sousa Barbosa 1, Marília Freitas Santana 1, Lara Moreira Ferreira 1, Maria Suelly Nogueira Pinheiro 1, Rondineia de Jesus Silva 1, Liane Carvalho de Brito de Souza 1, Washington Aspilicueta Pinto Filho 2, Carlos Eduardo Barros Jucá 2.

${ }^{1}$ Walter Cantídio University Hospital, Federal University of Ceará, Fortaleza, CE, Brazil.

${ }^{2}$ Albert Sabin Children's Hospital, Fortaleza, CE, Brazil.

*Corresponding author: Gabriele Sousa Barbosa. - R. Pastor Samuel Munguba, 1290 - Rodolfo Teófilo. Zip Code: 60430-372 - Ceará, CE, Brazil. Phone: +55 (85) 9 9713-6906. E-mail: gabrielesousabarbosa@alu.ufc.br

Research Ethics Committee Approval (if necessary): Approved by the Hospital Infantil Albert Sabin Ethics Committee (\#2.314.838).

Received on: Nov 1, 2021. Accepted on: Jan 4, 2022. Available online: Jan 19, 2022.

\begin{abstract}
Hydrocephalus is a common condition of accumulation of cerebral spinal fluid in the ventricular system. Generally, infants show with progressive macrocephaly or signs and symptoms of intracranial hypertension. The ventricular shunt represents a common and important treatment of hydrocephalus. However, it can occur some complications. The authors report a case of an accident of catheter removal in an infant, which the choroid plexus was removed by accident, and discuss how to diagnose and how to prevent it.
\end{abstract}

Keywords: Ventricular shunt; Hydrocephalus; Complications.

\section{Introduction}

Hydrocephalus is a condition in which an accumulation of cerebrospinal fluid (CSF) occurs within the ventricular system; it's supposed that 1:1.000 newborns could have this disease. However, some conditions in infants allowed hydrocephalus, like infections, post hemorrhagic or tumors. The standard approach for these problems is to insert a shunt between ventricular and peritoneal space, ventricular shunt (VS).

This shunt has a huge rate of complications, among them, there is the shunt malfunction. It usually occurs $50 \%$ per year [1]. During revision surgeries, there are clinical and surgical problems, one of the surgical problems is intraventricular bleeding [1]. We intended to describe a case report which 
the choroid plexus was removed by accident, a severe surgical complication.

\section{Case report}

Through a medical record review, we describe a case report of a 4-year-old child with an infant communicating hydrocephalus. At 6 months of life, the cephalic perimeter was above the $95 \%$ percentile predicted to age, treated with VS. Within 3 days, the patient presented a sudden change of consciousness along with irritability and vomiting. After hospitalization, to perform a tomographic study (Figure 1A), presented bradycardia and hemodynamic instability.

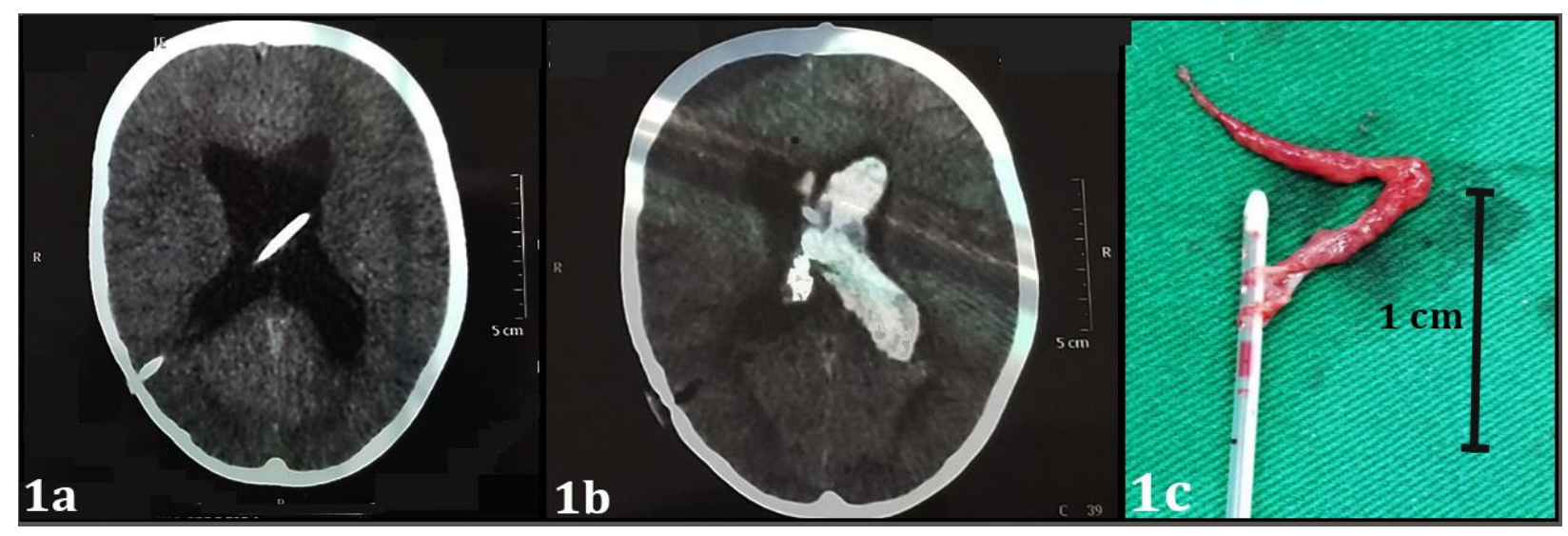

Figure 1. A. Cranial computed tomography (CT). B. Cranial CT with major bleeding. C. Choroid plexus removed by accident.

There was an immediate review of the VS, during the surgical procedure, after distal catheter removal and valve in the right parietal incision, a compression fracture of the hemostatic forceps of the proximal catheter next to the skull cap osteotomy occurred. Therefore, the proximal catheter was removed due to risk of massive cerebrospinal fluid leakage, important intracranial hypertension, and catheter interiorization. During the removal procedure, a brain tissue removal accident occurred (Figure 1C). It was opted for an external VS through the same orifice previous and observation of the intraventricular bleeding.

The patient was dispatched to the ward to the spontaneous resolution of minor intraventricular bleeding, constant in the external VS. However, it was observed on tomography on the 3rd day postoperative day that the bleeding increased (Figure 1B). After 20 days of surgical revision, the liquor drainage was practically negative for red blood cells, negative cultures and low proteins, being possible to replace the VS.

During hospitalization, the patient received prophylactic antibiotics 
for the VS, despite negative cultures. In addition, hematocrit decreased and hemotransfusion was necessary. After the 4th postoperative day of definitive VS implantation, the patient was discharged home.

\section{Discussion and Conclusion}

In general, a multimodality approach is necessary for the diagnosis of shunt malfunction, it is needed to set images (tomography, magnetic resonance, ventriculography), laboratory and clinical exams. The most notable signs and symptoms of shunt failure are nausea and vomiting, irritability, decreased level of consciousness and a bulging fontanel. These signs and symptoms gathered elevated up to $100 \%$ positive predictive value test [2]. The two most likely sites of obstruction are the ventricular/proximal catheter, which can be blocked by choroid plexus, and the shunt valve, which can be blocked by blood and debris. Other substances could be the origin of the bulk, like protein, brain parenchyma, ependymal cells, glial tissue, connective tissue and leptomeninges [3].

Some shunt taps have a rescue system to avoid CSF blockage, neurosurgeons could use it. When they need to remove the shunt system, careful movements are required. In rare events, the proximal catheter that was removed from the ventricular place could provoke intracerebral bleeding, which happened in the case reported. This bleeding is resolved by external shunt, it is possible the CSF hemorrhage lasts several days until stopped permanent.

Other strategies are open craniotomy, decompressive craniectomy, neuroendoscopy, and minimally invasive catheter evacuation followed by thrombolysis. These surgeries have a serious impact on patient prognostic [4]. There are some tips to predicted proximal catheter misplacement: 1deeper proximal catheter localization, 2previous history of infection or hemorrhage, 3-slit-ventricle syndrome, 4- coagulation disorders, 5- proximal catheter jammed [5].

We concluded that the neurosurgeons could avoid careless maneuvers during surgeries and be aware of catheter misplacement which could be jammed deeper in the choroid plexus.

\section{References}

[1] McGirt MJ, Leveque JC, Wellons JC 3rd, Villavicencio AT, Hopkins JS, Fuchs HE, George TM. Cerebrospinal fluid shunt survival and etiology of failures: a seven-year institutional experience. Pediatr Neurosurg. 2002 May;36(5):24855. doi: $10.1159 / 000058428$.

[2] Garton HJ, Kestle JR, Drake JM. Predicting shunt failure on the basis of clinical symptoms and signs in children. 
J Neurosurg. 2001 Feb;94(2):202-10. doi: 10.3171/jns.2001.94.2.0202.

[3]- Jeremiah KJ, Cherry CL, Wan KR, Toy JA, Wolfe R, Danks RA. Choice of valve type and poor ventricular catheter placement: Modifiable factors associated with ventriculoperitoneal shunt failure. J Clin Neurosci. 2016 May; 27:95-8. doi: 10.1016/j.jocn.2015.07.026.

[4] de Oliveira Manoel AL. Surgery for spontaneous intracerebral hemorrhage. Crit Care. 2020 Feb 7;24(1):45. doi: 10.1186/s13054-020-2749-2.

[5] Sivaganesan A, Krishnamurthy R, Sahni D, Viswanathan C. Neuroimaging of ventriculoperitoneal shunt complications in children. Pediatr Radiol. 2012 Sep;42(9):1029-46. doi: 10.1007/s00247-012-2410-6. Epub 2012 Jun 28.

Conflict of interest: The author declares no conflicts of interest.

Acknowledgements: None.

Funding: None.

How to cite this article: Barbosa GS, Santana MF, Ferreira LM, Pinheiro MSN, Silva RJ, Souza LCB, Pinto Filho WA, Jucá CEB. Unusual accident during proximal ventricular shunt catheter removal in an infant: a case report. Brazilian Journal of Case Reports. 2022 Jan-Mar;02(1):40-43. 